\title{
Polyamine and intestinal properties in adult rats
}

\author{
BY PATRICIA DELOYER ${ }^{1}$, GUY DANDRIFOSSE ${ }^{1 *}$, \\ CATHERINE BARTHOLOMEUS ${ }^{1}$, NADINE ROMAIN ${ }^{1}$, MONIQUE KLIMEK ${ }^{1}$, \\ JOSÉ SALMON ${ }^{1}$, PAUL GÉRARD ${ }^{2}$ AND GUY GOESSENS ${ }^{3}$ \\ ${ }^{1}$ Department of Biochemistry and General Physiology, ${ }^{2}$ Department of Statistics and \\ ${ }^{3}$ Laboratory of Biology, Liege University, Sart Tilman, 4000 Liege, Belgium
}

AND HENDRIK EYSSEN

Rega Institute for Medical Research, Katholieke Universiteit Leuven, 3000 Leuven, Belgium

(Received 13 October 1993 - Revised 29 November 1995 - Accepted 17 January 1996)

\begin{abstract}
We questioned whether polyamines coming from the diet or produced by intestinal microflora or by intracellular metabolism influence intestinal functions. Therefore, we compared pathogen-free rats and germ-free rats receiving a diet with low polyamine content and either treated or not treated with difluoromethylornithine (DFMO) and/or methylglyoxal bis (guanylhydrazone) (MGBG). Wet weight, protein content, DNA content, sucrase $(E C 3.2 .1 .48)$, maltase $(E C 3.2 .1 .20)$ and lactase (EC 3.2.1.23) specific activities, amounts of putrescine, spermidine and spermine were measured in the mucosa of the proximal and distal intestine. Body weight was also determined. Rats without microflora had a higher specific activity of maltase and higher amounts of spermidine and spermine but lower lactase specific activity than pathogen-free animals; the low-polyamine diet given to germ-free rats had little effect on the functional variables measured (decrease of maltase and lactase specific activities) and did not modify the amounts of polyamines. DFMO and/or MGBG administered to germ-free rats receiving a low-polyamine diet induced modifications of most of the variables studied. Body weight and wet weight of proximal and distal intestine decreased, disaccharidase specific activities decreased, and amounts of polyamines changed according to the inhibitor used. Thus, our results showed that the deprivation of polyamine supply from microflora or from the diet failed, under our experimental conditions, to affect the intestinal properties analysed but exogenous and endogenous polyamine restriction altered general properties of the organism as well as intestinal functions.
\end{abstract}

Polyamines: Spermine: Spermidine: Intestinal function

The polyamines (putrescine, spermidine and spermine) are ubiquitous polycationic compounds found in all cell types (Jänne et al. 1978; Pegg \& McCann, 1982). They are mainly associated with initiation of rapid cellular growth and differentiation in the intestinal mucosa (for reviews, see Luk \& Baylin, 1983; Hosomi et al. 1985).

We have previously shown that spermine and spermidine, provided orally, induce in the intestine structural and biochemical mucosal changes, characteristic of postnatal maturation (Dufour et al. 1988). Our studies also indicate that spermine-induced precocious postnatal intestinal maturation is reversible when spermine treatment is stopped (Georges et al. 1990). Other authors (Luk et al. 1980) have established that $\alpha$-difluoromethylornithine (DFMO), an inhibitor of ornithine decarboxylase (EC 4.1.1.17; ODC), one of the key enzymes controlling polyamine metabolism, produces a delay in the intestinal maturation process. As adult rat diet contains high polyamine levels compared with rat milk (Pollack et al. 1992; Romain et al. 1992), these observations suggest several questions. Are

\footnotetext{
* For reprints.
} 
polyamines, in the adult rat, playing a role in the maintenance of maturational stage of enterocytes? Could a decrease of dietary and/or endogenous supplies of polyamines cause dedifferentiation of these cells?

To answer these questions we tried to reduce, where possible, all sources providing polyamines to the intestine. By using germ-free rats we avoided the polyamine supply from the intestinal microflora. Dietary polyamines were reduced by giving a specially defined diet to the rats. Endogenous synthesis of polyamines was limited by administration of DFMO and methylglyoxal bis (guanylhydrazone) (MGBG) which inhibits activity of Sadenosylmethionine decarboxylase (EC 4.1.1.50; SAMDC), another important enzyme of polyamine metabolism, and decreases plasma membrane permeability to polyamines.

We observed the effects of these treatments by measuring variables relating to the maturational stage of the enterocytes: disaccharidase activities (high sucrase (EC 3.2.1.48) and maltase ( $E C 3.2 .1 .20)$ activities and low lactase (EC 3.2.1.23) activity are characteristic of adult rat intestine), and histological aspects of the enterocytes (the presence of large supranuclear vacuoles and a canalicular system is characteristic of immature intestine, especially in the distal part). We also measured protein, DNA and polyamine contents.

\section{MATERIALS AND METHODS}

Test groups

Germ-free Wistar rats (Rega Institute, Leuven, Belgium; 2 months old) were used in all experiments. All animals were housed in Trexler's flexible-film plastic isolators (Standard Safety Equipment, Palatine, IL, USA), at $23^{\circ}\left( \pm 1^{\circ}\right)$ and $50-60 \%$ humidity, with $15 \mathrm{~h}$ of daylight. The rats of each group of a given experiment were kept in the same cage. The animals received autoclaved, canned water and feed ad libitum. Unless stated otherwise, the feed was Mucaron G pellets (Trouw N.V., Gent, Belgium; polyamine content: putrescine, $693 \mathrm{nmol} / \mathrm{g}$; spermidine, $182 \mathrm{nmol} / \mathrm{g}$; spermine, $33.6 \mathrm{nmol} / \mathrm{g}$ ).

In a first experiment, ten rats were used. They were divided into two groups of five animals. The first group (called 'germ-free') was maintained under the standard conditions described previously. The rats of the second group (called 'control') were conventionalized at the age of 3 weeks by being kept for at least $39 \mathrm{~d}$ in close contact with Wistar rats of the same age with normal intestine microflora (pathogen-free animals). The rats of both groups received the sterile feed mentioned above. When they were 2 months old, they were killed by cerebral dislocation, after ether anaesthesia.

In a second experiment, twenty rats were used. Four animals (also called 'germ-free'), were treated exactly like the germ-free animals of the first experiment. Eight other germfree rats (called 'special diet') received a totally purified diet (Chauveau et al. 1951). This diet contained low contents of polyamines (putrescine : $4.0 \mathrm{nmol} / \mathrm{g}$, spermidine : $4.4 \mathrm{nmol} / \mathrm{g}$, and spermine: $0 \cdot 1 \mathrm{nmol} / \mathrm{g}$ ) and was sterilized by irradiation (IRE, Belgium). The last eight germ-free rats (named 'DFMO') received the purified diet together with DFMO in drinking water ( $20 \mathrm{~g} / 1)$. DFMO (a gift from Merrel Dow Institute, Strasbourg, France) was sterilized for $30 \mathrm{~min}$ at $120^{\circ}$ in sealed tubes (dry DFMO does not deteriorate in these conditions: personal communication from Merrel Dow Institute). The 'special diet' and 'DFMO' treatments lasted for $7 \mathrm{~d}$. Then the rats were killed as reported previously.

In the third experiment, fifteen germ-free rats were used. Five animals (called 'special diet') were treated like the 'special diet' animals of the second experiment. They received an i.p. injection of saline $(9 \mathrm{~g} \mathrm{NaCl} / 1,0 \cdot 2 \mathrm{ml}$ ), once daily, for $3 \mathrm{~d}$. Five animals (called ' $M G B G$ ') received the synthetic diet and an i.p. injection of MGBG ( $5 \mathrm{mg} / 0 \cdot 2 \mathrm{ml}$ saline), once daily, for $3 \mathrm{~d}$. The last five animals (called 'DFMO+MGBG') received the purified diet, DFMO and MGBG treatment as described previously. Afterwards, all the rats were killed as already reported. 
Tissue extract

After cerebral dislocation, the small intestine was immediately removed, then washed in cold saline $\left(9 \mathrm{~g} \mathrm{NaCl} / 1,4^{\circ}\right)$. The length of the small intestine was measured then it was divided into two equal parts called 'proximal intestine' (including the duodenum) and 'distal intestine'. From each part a $10 \mathrm{~mm}$ fragment was immediately immersed in Bouin's liquid for histological examination and small biopsies $( \pm 1 \mathrm{~mm}$ diameter) were fixed in glutaraldehyde for examination under an electron microscope. The mucosa of the remainder of each part of the small intestine was gently dried with filter paper. It was removed by scraping then weighed and homogenized in distilled water $(1 \mathrm{~g}$ wet weight $/ 4.15 \mathrm{ml}$ ) using a homogenizer (B. Braun, Melsungen AG, Melsungen, Germany) equipped with glass pestle and tube. The homogenate was kept in portions maintained at $-70^{\circ}$ until analysis.

\section{Enzyme activities}

Sucrase, maltase and lactase activities were assayed according to Dahlqvist (1968), as reported previously (Forget et al. 1985). The enzyme activities were expressed as $\mu \mathrm{mol}$ substrate hydrolysed/min. They were related to $1 \mathrm{~g}$ intestinal proteins (specific activity, SA).

\section{Protein content}

The protein content of the homogenates was estimated by Bradford's method (Bradford, 1976) using bovine serum-albumin (Boehringer Mannheim, Germany) as protein standard. It was expressed as $\mathrm{mg} / \mathrm{g}$ wet weight of tissue or organ.

\section{DNA content}

DNA content was estimated by Schneider's procedure (Schneider, 1957) using calf thymus DNA (Boehringer Mannheim) as standard. It was expressed as $\mathrm{mg} / \mathrm{g}$ protein.

\section{Polyamine content}

The polyamine content was measured by HPLC (Bontemps et al. 1984). It was expressed as $\mathrm{mg} / \mathrm{g}$ protein. The polyamines were dansylated (Brown \& Strickler, 1982) and subsequently separated on a reversed-phase column (Lichrocart RP-18, Merck-Hitachi system, Instrument Division Hitachi Ltd, Ibarakiken, Japan).

\section{Histological studies}

Intestinal segments were fixed in Bouin's liquid, dehydrated and embedded in paraffin. Sections were prepared, stained with haematoxylin and eosin and examined by light microscopy. Small biopsies (about $1 \mathrm{~mm}$ diameter) were fixed for $120 \mathrm{~min}$ in $25 \mathrm{ml} / 1$ glutaraldehyde diluted in a cacodylate buffer at $\mathrm{pH} 7 \cdot 4$. They were postfixed for $60 \mathrm{~min}$ in osmic acid $(10 \mathrm{~g} / 1)$ and, after dehydration, were embedded in Epon. After cutting and staining, preparations were examined under an electron microscope (Siemens 101, Siemens AG, Berlin, Germany; $80 \mathrm{kV}$ ).

\section{Statistical analysis}

The results are reported as means with their standard errors. Statistical analysis was accomplished using unpaired Student's $t$ test, and one-way ANOVA for comparison between groups. Behrens-Fisher and Kruskall Wallis tests were used when heteroscedasticity was suspected.

\section{RESULTS}

In the rat, body weight and wet weight of the proximal and distal intestine were little affected by the absence of intestinal microflora (Table 1), by low-polyamine diet ingestion (Table 2) or by MGBG treatment (Table 3). However, the ingestion of DFMO $(20 \mathrm{~g} / \mathrm{l}$ in 
Table 1. Influence of germ-free status on body and small intestine weight, and on protein content in rats

(Mean values with their standard errors for five rats per group)

\begin{tabular}{|c|c|c|c|c|c|}
\hline & \multirow{2}{*}{$\begin{array}{l}\text { Small } \\
\text { intestine } \\
\text { segment }\end{array}$} & \multicolumn{2}{|c|}{ Control rats } & \multicolumn{2}{|c|}{ Germ-free rats } \\
\hline & & Mean & SEM & Mean & SEM \\
\hline Body wt (g) & & $127 \cdot 0$ & $2 \cdot 7$ & $124 \cdot 0$ & $8 \cdot 2$ \\
\hline \multirow[t]{2}{*}{ Wet wt $(\mathrm{g})$} & Proximal & $1 \cdot 13$ & 0.09 & $1 \cdot 29^{*}$ & 0.07 \\
\hline & Distal & 0.86 & $0-08$ & 0.77 & 0.08 \\
\hline \multirow{2}{*}{$\begin{array}{r}\text { Protein content } \\
(\mathrm{mg} / \mathrm{g} \text { wet wt) }\end{array}$} & Proximal & $106 \cdot 3$ & $10-4$ & $101 \cdot 8$ & $16 \cdot 3$ \\
\hline & Distal & $95 \cdot 5$ & $9 \cdot 3$ & $85 \cdot 1$ & 6.0 \\
\hline
\end{tabular}

* Mean value was significantly different from that for control rats $(P \leqslant 0-05)$.

Table 2. Influence of a low-polyamine purified diet and difluoromethylornithine (DFMO) on body and small intestine weights, and on intestinal protein and DNA contents in germfree rats

(Mean values with their standard errors)

\begin{tabular}{|c|c|c|c|c|c|c|c|}
\hline & \multirow{2}{*}{$\begin{array}{c}\text { Small } \\
\text { intestine } \\
\text { segment }\end{array}$} & \multicolumn{2}{|c|}{ Germ-free rats } & \multicolumn{2}{|c|}{ Purified diet rats } & \multicolumn{2}{|c|}{ DFMO rats } \\
\hline & & Mean $(n 4)$ & SEM & Mean $(n 8)$ & SEM & Mean $(n 8)$ & SEM \\
\hline Body wt (g) & & $126 \cdot 0$ & $5 \cdot 2$ & $125 \cdot 0$ & $6 \cdot 9$ & $110.9 \dagger$ & $7 \cdot 2$ \\
\hline \multirow[t]{2}{*}{ Wet wt (g) } & Proximal & 1.35 & 0.12 & $1 \cdot 31$ & $0 \cdot 12$ & $0.84 *$ & 0.08 \\
\hline & Distal & 0.76 & 0.12 & 0.80 & 0.13 & $0.64 \uparrow$ & 0.08 \\
\hline \multirow{2}{*}{$\begin{array}{l}\text { Protein content } \\
(\mathrm{mg} / \mathrm{g} \text { wet wt) }\end{array}$} & Proximal & $158 \cdot 2$ & $32 \cdot 3$ & $163 \cdot 2$ & $15 \cdot 9$ & 153.6 & $9 \cdot 6$ \\
\hline & Distal & 123.5 & 29.8 & $122 \cdot 4$ & $30 \cdot 4$ & $138 \cdot 5$ & $10 \cdot 9$ \\
\hline \multirow{2}{*}{$\begin{array}{l}\text { DNA content } \\
(\mathrm{mg} / \mathrm{g} \text { protein })\end{array}$} & Proximal & $49 \cdot 3$ & 7.2 & $52 \cdot 8$ & $13 \cdot 0$ & $35 \cdot 1 *$ & 3.7 \\
\hline & Distal & $38 \cdot 8$ & $2 \cdot 7$ & $39 \cdot 6$ & $5 \cdot 5$ & $36 \cdot 5$ & $3 \cdot 7$ \\
\hline
\end{tabular}

* Mean values were significantly different from germ-free or purified diet rats, $P<0.05$.

$\dagger$ Mean values were significantly different from purified diet rats, $P<0.05$.

$\$$ For details of diets and procedures, see pp. 628-629.

Table 3. Influence of methylglyoxal bis (guanylhydrazone) (MGBG) and difluoromethylornithine (DFMO) plus $M G B G$ on the weights of the body and small intestine, and on protein and DNA contents in germ-free rats receiving a low-polyamine, purified diet $\dagger$

(Mean values with their standard errors)

\begin{tabular}{|c|c|c|c|c|c|c|c|}
\hline & \multirow{2}{*}{$\begin{array}{c}\text { Small } \\
\text { intestine } \\
\text { segment }\end{array}$} & \multicolumn{2}{|c|}{ Purified diet rats } & \multicolumn{2}{|c|}{ MGBG rats } & \multicolumn{2}{|c|}{$\mathrm{DFMO}+\mathrm{MGBG}$ rats } \\
\hline & & Mean ( $n$ 5) & SEM & Mean ( $n$ 5) & SEM & Mean ( $n$ 5) & SEM \\
\hline & & $119 \cdot 2$ & $3 \cdot 7$ & $113 \cdot 8$ & $12 \cdot 9$ & $96.0^{*}$ & $6 \cdot 5$ \\
\hline \multirow[t]{2}{*}{ Wet wt (g) } & Proximal & $1 \cdot 29$ & 0.07 & $1 \cdot 21$ & $0 \cdot 17$ & $0.58 *$ & $0 \cdot 16$ \\
\hline & Distal & 0.85 & $0 \cdot 14$ & $0 \cdot 71$ & 0.18 & $0 \cdot 39 *$ & $0 \cdot 18$ \\
\hline \multirow{2}{*}{$\begin{array}{r}\text { Protein content } \\
(\mathrm{mg} / \mathrm{g} \text { wet wt) }\end{array}$} & Proximal & $155 \cdot 1$ & $3 \cdot 9$ & $144 \cdot 2$ & $13 \cdot 5$ & $145 \cdot 3$ & $8 \cdot 6$ \\
\hline & Distal & $119 \cdot 8$ & $11 \cdot 7$ & $120 \cdot 5$ & $7 \cdot 8$ & $109 \cdot 5$ & $4 \cdot 6$ \\
\hline \multirow{2}{*}{$\begin{array}{l}\text { DNA content } \\
\text { (mg/g protein) }\end{array}$} & Proximal & $58 \cdot 3$ & $8 \cdot 8$ & $53 \cdot 0$ & $5 \cdot 0$ & 63.6 & $7 \cdot 5$ \\
\hline & Distal & $36 \cdot 5$ & $3 \cdot 2$ & $38 \cdot 5$ & $2 \cdot 7$ & $36 \cdot 3$ & $2 \cdot 3$ \\
\hline
\end{tabular}

* Mean values were significantly different from those for the purified diet and MGBG groups, $P<0.05$.

$\dagger$ For details of diets and procedures, see pp. 628-629. 
Proximal
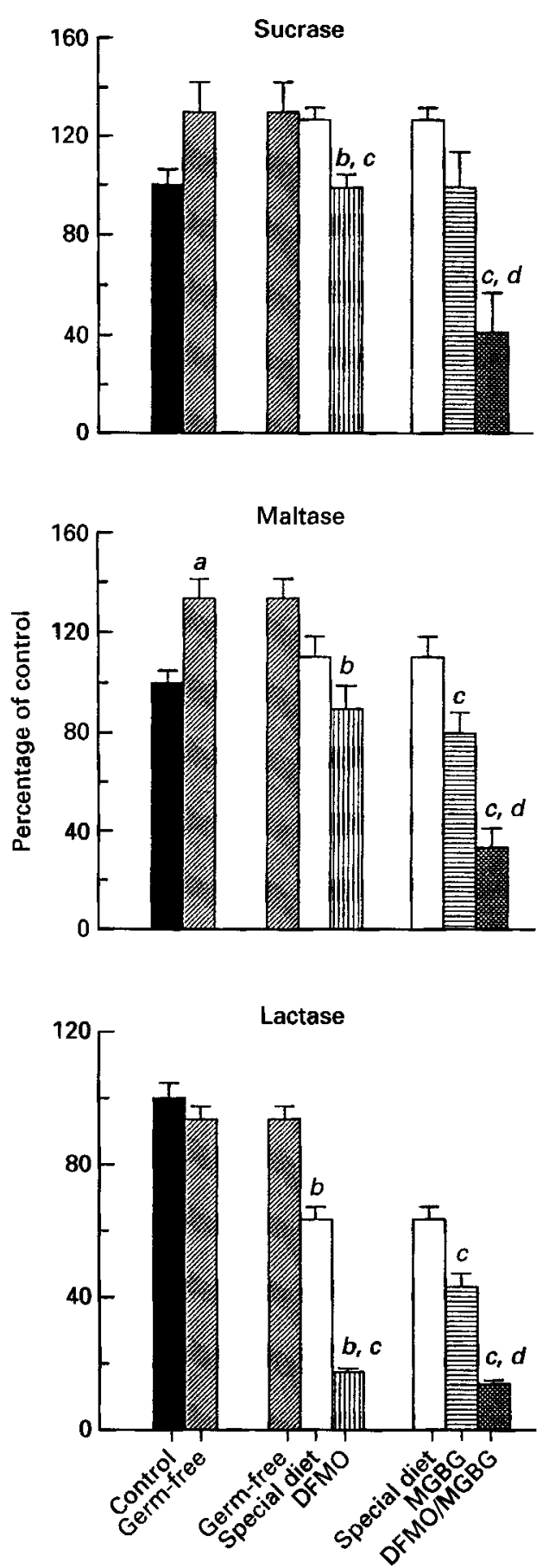

Distal

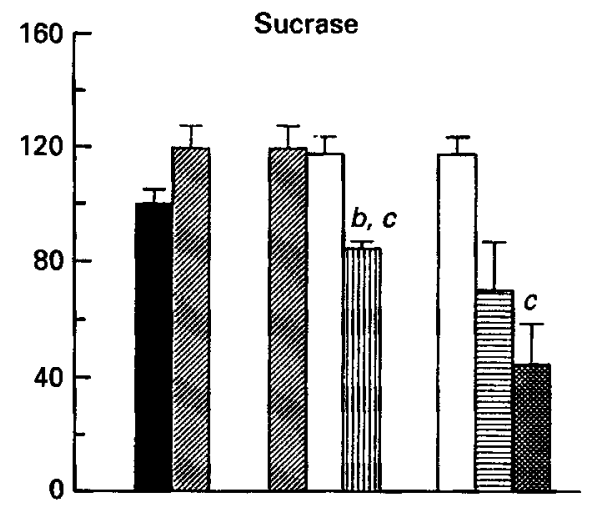

Maitase
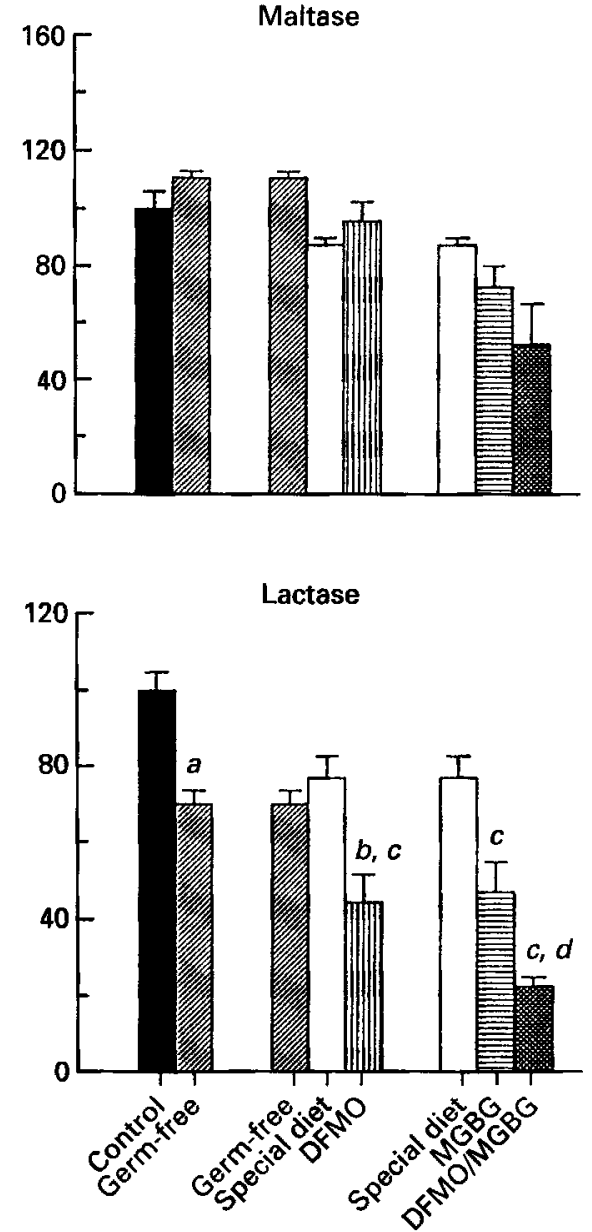

Fig. 1. Effect of polyamine deprivation on disaccharidase specific activities in the rat intestine. Values are means with their standard errors indicated by vertical bars. Mean value was significantly different from that of: $a$, the control group; $b$, the germ-free group; $c$, the special diet group; $d$, the methylglyoxal bis (guanylhydrazone) (MGBG)-treated group $(P<0.05)$. DFMO, difluoromethylornithine. 
Proximal
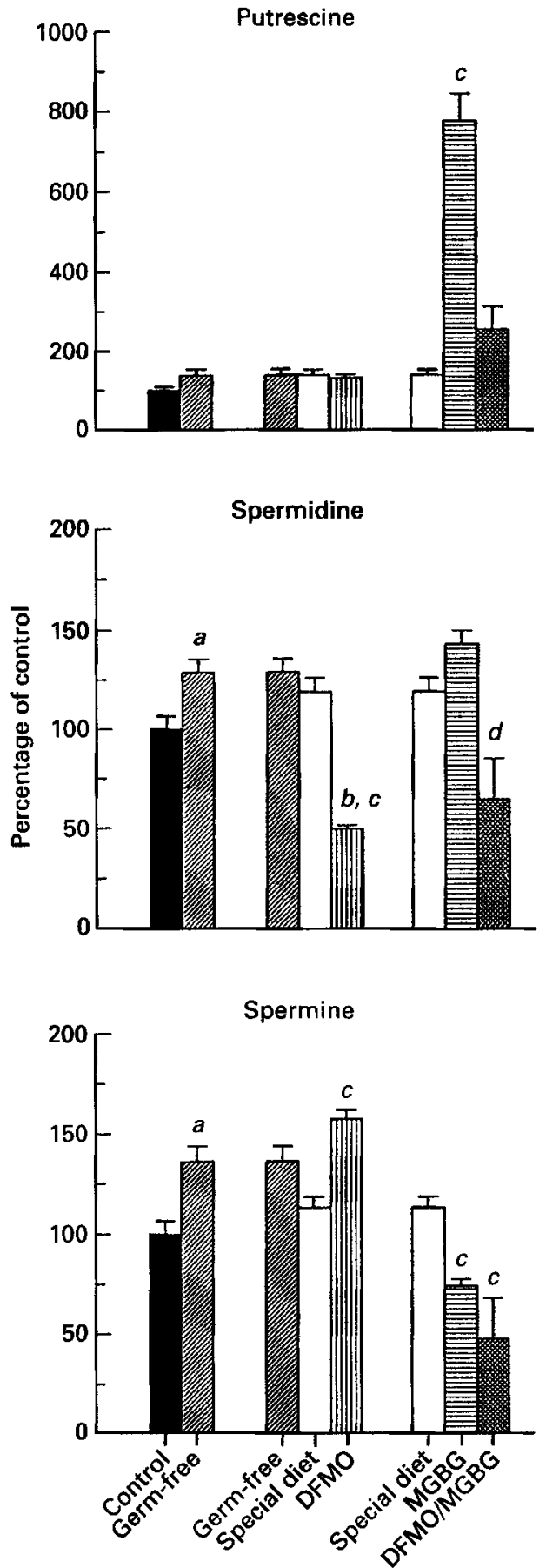

Distal

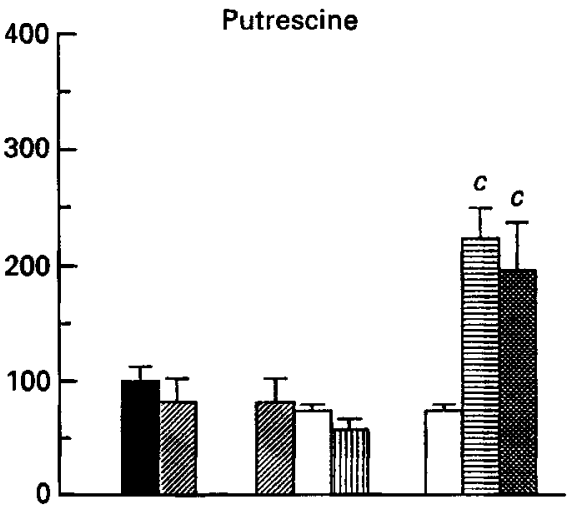

Spermidine
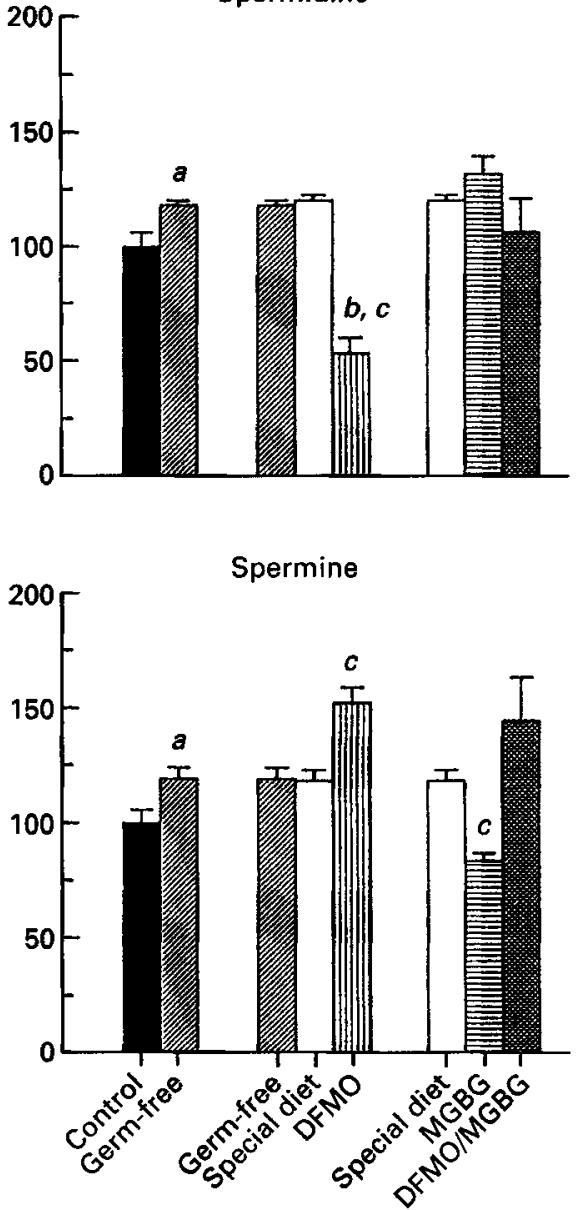

Fig. 2. Effect of polyamine deprivation on polyamine content in the rat intestine. Values are means with their standard errors indicated by vertical bars. Mean value was significantly different from that of: $a$, the control group; $b$, the germ-free group; $c$, the special diet group; $d$, the methylglyoxal bis (guanylhydrazone) (MGBG)treated group $(P<0-05)$. DFMO, difluoromethylornithine. 
drinking water) for $7 \mathrm{~d}$ by germ-free rats receiving the purified diet without MGBG (Table 2) or with MGBG (Table 3) induced significant decreases in these morphological variables.

Protein and DNA contents were generally not modified, whatever the treatment applied (Tables 1-3). We observed no significant variation in these variables except in the case of the DNA content, which decreased in the proximal intestine of the germ-free rats receiving the low-polyamine diet and treated with DFMO (Table 2). Surprisingly, this was not observed when DFMO and MGBG were administered together to these animals (Table 3).

The germ-free group showed significantly modified disaccharidase SA (Fig. 1) compared with the control group: maltase SA increased in the proximal intestine and lactase SA decreased in the distal part. Ingestion of the low-polyamine diet by germ-free rats induced significant diminution of lactase SA in the proximal part of the intestine (Fig. 1). Additional treatment of the animals with DFMO and/or MGBG generally produced a strong decrease of the three disaccharidase SA (Fig. 1) in the whole intestine.

Spermidine and spermine contents in both parts of the intestine were higher in the germfree group than in the control group (Fig. 2). Ingestion of the low-polyamine diet by germfree rats had no significant effect on these variables. When these rats received DFMO there was no change in putrescine content but a significant decrease in spermidine content and an increase in spermine content were observed. In MGBG rats, compared with special diet animals, putrescine content dramatically increased and spermine content decreased in the whole intestine. No change was noted concerning spermidine content. When the DFMO + MGBG treatment was administered to germ-free rats receiving the lowpolyamine diet, spermidine and spermine contents were reduced in the proximal intestine and putrescine content increased in the distal intestine.

No structural (results not shown) or ultrastructural modification was detected in any of the experimental conditions chosen, except when MGBG was administered to animals. Then, the mitochondria appeared swollen and the endoplasmic reticulum seemed to be less dense.

\section{DISCUSSION}

In order to elucidate the role of polyamines in intestinal differentiation and function, we minimized the in vivo availability of these compounds for adult rat enterocytes. As we have already shown that the ingestion of spermine or spermidine can induce precocious intestinal maturation in sucking rats (Dufour et al. 1988) and that this phenomenon is reversible when polyamine treatment is stopped (Georges et al. 1990), we expected to observe a dedifferentiation or a 'dematuration' of the adult enterocytes after decreasing the intracellular polyamine content.

We tried to increase the severity of polyamine deprivation by reducing, step by step, sources contributing to polyamine homeostasis, i.e. successively, intestinal microflora, polyamines in diet, polyamine endogenous synthesis and plasma membrane permeability to polyamines.

Whatever the treatment applied, we never observed modifications of variables indicating a 'dematuration' of enterocytes, i.e. a decrease in maltase and sucrase SA, an increase in lactase SA, or a modification in the ultrastructural aspect of distal enterocytes. Indeed, except for maltase in the proximal intestine of germ-free rats, the reduction of polyamine supply induced a decrease of the three disaccharidase SA (Fig. 1). There was never an increase of lactase SA. Moreover, histological observations showed no appearance of large supranuclear vacuoles in enterocytes (results not shown), characteristic of the distal intestine in unweaned rats. This contrasts with reversible spermine-induced intestinal maturation in sucking rats (Georges et al. 1990). Consequently, during the period of weaning or just after this period, irreversible modifications of genes contained in the crypt stem cells must occur. These changes could be controlled by the biological clock, which is 
implicated in intestinal development (Diamond, 1986; Gordon \& Hermiston, 1994), or could result from the new hormonal status of the animals which appears after or during weaning.

Otherwise, our data allowed us to analyse the impact of a restriction of polyamines coming from the diet, the intestinal flora or the intracellular metabolism on intestinal variables in the adult rat.

Reduction of exogenous polyamine supply, by using germ-free rats fed with or without a low-polyamine diet, had little effect on trophic variables such as body weight and intestinal wet weight, or on intestinal protein content and DNA content (Tables 1, 2). However, inhibition of polyamine biosynthesis, especially by DFMO, associated with absence of intestinal microflora and low-polyamine diet, induced a significant decrease of some of these variables (Tables 2,3$)$. As DFMO alone $(20 \mathrm{~g} / 1$ in drinking water; daily consumption of $2-2.6 \mathrm{~g} / \mathrm{kg}$ per d), administered for $14 \mathrm{~d}$, has no detectable effect on the small intestine of adult rats (Luk et al. 1980), it may be suggested that a depletion of exogenous polyamines associated with DFMO treatment alters the trophic characteristics cited previously. However, if DFMO ingestion is increased to $4 \mathrm{~g} / \mathrm{kg}$ per $\mathrm{d}$, feed consumption is reduced and intestinal wet weight decreases (Alarcon et al. 1987). We did not measure the feed consumption. Thus, we may not exclude the possibility that this variable was reduced when DFMO treatment was given in association with restriction of exogenous polyamine supply. In further experiments we will try to use a pair-feeding arrangement.

The present results obtained from DFMO-treated germ-free rats receiving the lowpolyamine diet are quite similar to those reported by Moulinoux et al. (1991). These authors showed that inhibition of polyamine metabolism resulting from DFMO ingestion, associated with gut 'antibiotic cleaning' and low-polyamine-diet consumption, induces a decrease of tumour weight in mice, i.e. affects a trophic variable. Thus, important endogenous and exogenous restriction of polyamine supply decreases cancer proliferation as well as intestinal weight as in the present experiments.

Concerning intestinal functional properties, we estimated only disaccharidase SA, our goal being to evaluate a possible dedifferentiation of enterocytes. As described previously, restriction of polyamine supply from exogenous and endogenous sources reduced, sometimes very strongly, the disaccharidase SA (Fig. 1). Lactase was the most sensitive enzyme. Its SA in the distal intestine decreased in the absence of microflora. Such a reduction occurred also in the proximal intestine of the special diet animals and its severity increased in accordance with the level of polyamine restriction (less than $20 \%$ of the control values in the DFMO-MGBG group). Sucrase and maltase SA were altered when polyamine biosynthesis inhibitors were used with exogenous polyamine deprivation. These results might be explained, in most cases, by a significant atrophy of the intestine (DFMO and DFMO-MGBG groups, Tables 2 and 3 respectively): intestinal atrophy with shortened villi and relatively elongated crypt regions was described after DFMO treatment in dog and in monkey (Yarrington et al. 1983). Thus, our observations could result from the existence of less mature villi in DFMO- and/or MGBG-treated rats. Moreover, Yarrington et al. (1983) and Ittel et al. (1992) showed that, following DFMO administration, enterocytes develop altered brush borders (shorter and less numerous microvilli), without general atrophy of the mucosa. From our present results we can suggest that the low-DFMO treatment that we employed (which did not affect intestinal properties in adult pathogen-free rats), associated with reduction of exogenous polyamine supply, had the same effect as high doses of DFMO administered alone. Surprisingly, our results showed that this fact was not associated with a large decrease of polyamine content in the intestine. 
From another point of view, it has to be noticed that there were differences in the feed composition of the germ-free rats and of the special diet animals. The latter received lowpolyamine feed prepared in our laboratory, following Chauveau's indications (Chauveau et al. 1951), in order to minimize exogenous polyamine supply. The differences in feed composition could also explain the disaccharidase SA modifications observed in the special diet group compared with the germ-free group, suggesting an adaptation of the gut to the new diet.

As described previously, the progressively severe restriction of polyamine availability did not drastically reduce polyamine contents in the intestinal mucosa. Following the treatment applied, an increase or a decrease of each polyamine content was observed. First, the absence of intestinal microflora induced a significant increase of spermidine and spermine contents in the proximal as well as in the distal part of the intestine (Fig. 2). What is the origin and the mechanism of these modifications? It is possible (1) that endogenous biosynthetic adaptation occurs, with an increase of ODC and SAMDC activities; (2) that luminal uptake of dietary polyamines is enhanced in the intestine of the germ-free rats; (3) that polyamines from the body pool are transported preferentially into the intestinal cells (basolateral uptake). These two last hypotheses are supported by the work carried out by Bardócz and Pusztai (Bardócz et al. 1990, 1991, 1995). These authors showed that stimulation of basolateral transport of polyamines is observed when the growth of the small intestine is induced by phytohaemagglutinin or by refeeding, and proved the importance of luminal polyamine absorption, which could potentially cover the major part of body polyamine requirement.

What is the meaning of these modifications? We have no satisfactory answer to this question. We observed that absence of intestinal microflora induced a significant increase of mucosal wet weight in the proximal intestine (Table 1), an adaptation which could be related to a stimulation of cell proliferation and, thus, to higher polyamine requirements: but, the distal intestine, which contained, also, increased concentrations of spermidine and spermine, was not characterized by an augmentation of mucosal wet weight (Table 1).

Additional DFMO treatment, which irreversibly inhibits ODC activity, reduced by half the spermidine content (Fig. 2) in the intestinal mucosa. Putrescine content was maintained, probably from spermidine retroconversion. $\mathrm{MGBG}$, which inhibits SAMDC activity, induced strong putrescine content augmentation (Fig. 2), suggesting that ODC activity was greatly enhanced. Contrary to DFMO, this inhibitor had no effect on the content of spermidine and decreased that of spermidine. Although the interpretation of these results can generally be constructed on the basis of endogenous metabolic modifications of polyamines, it is also possible that polyamines from the body pool were implicated. Firm conclusions will be brought from a detailed analysis of polyamine enzyme concentrations and activities, and an estimation of the specific radioactivity of each polyamine in the intestinal mucosa from rats set in the experimental conditions cited in the present study.

Our results do not allow us to establish a clear correlation between morphological or functional variables of the intestine, such as disaccharidase SA, and polyamine contents estimated in the mucosa. This finding is not in conflict with the fact that progressive restriction of polyamine supply induced a decrease in the general properties of the gut. To explain this statement it would be better to take into consideration the evolution of the total polyamine body pool. Indeed, it has been suggested that body polyamine homeostasis depends on a balance between polyamine gut uptake (from food and bacteria), polyamine endogenous biosynthesis and polyamine inter-organ exchanges (Bardócz et al. 1991, 1995). When one of these polyamine sources is deficient, the others can compensate for the resulting deficiency. That is probably why the low-polyamine diet treatment lasting in our experiments for $7 \mathrm{~d}$, could be easily corrected. Further experiments on germ-free rats fed 
on a long-term low-polyamine diet are planned in order to determine what this particular diet, used during a more extended time, will do in terms of functional variables of the intestine and polyamine reserves of the organism.

In conclusion, our results suggest that the supply of polyamines by microflora or by the diet is not essential for the maintenance of intestinal properties and that a restriction of polyamines, both endogenous and exogenous, alters general properties (body weight, intestinal wet weight, intestinal protein and DNA content) of the organism as well as intestinal functions (disaccharidase activities).

This work was supported by a grant from the 'Service de la Programmation de la Politique Scientifique' (no. HH/006). The text presents research results of the Belgian Incentive Programme 'Health hazards' initiated by the Belgian State - Prime Minister's ServiceScience Policy Office. Scientific responsibility is accepted by its authors.

\section{REFERENCES}

Alarcon, P., Lebenthal, E. \& Lee, P. C. (1987). Effect of difluoromethyl ornithine (DFMO) on small intestine of adult and weaning rats. Digestive Diseases and Sciences 32, 883-888.

Bardócz, S., Brown, D. S., Grant, G. \& Pusztai, A. (1990). Luminal and basolateral polyamine uptake by rat small intestine stimulated to grow by Phaseolus vulgaris lectin phytohaemagglutinin in vivo. Biochimica et Biophysica Acta 1034, 46-52.

Bardócz, S., Duguid, T. C., Brown, D. S., Grant, G., Pusztai, A., White, A. \& Ralph, A. (1995). The importance of dietary polyamines in cell regeneration and growth. British Journal of Nutrition 73, 819-828.

Bardócz, S., Grant, G., Brown, D. S., Ewen, S. W. B., Stewart, J. C. \& Pusztai, A. (1991). Effect of fasting and refeeding on basolateral polyamine uptake and metabolism by the rat small bowel. Digestion 50, 28-35.

Bontemps, J., Laschet, J., Dandrifosse, G., Van Custem, J. L. \& Forget, P. (1984). Analysis of dansyl derivatives of di- and polyamines in mouse brain, human serum and duodenal biopsy by high-performance liquid chromatography on a standard reversed-phase column. Journal of Chromatography 311, 59-67.

Bradford, M. M. (1976). A rapid and sensitive method for the quantitation of microgram quantities of protein utilizing the principle of protein-dye binding. Analytical Biochemistry 72, 248-254.

Brown, N. D. \& Strickler, H. P. (1982). Femtomolar ion-pair high-performance liquid chromatographic method for determining Dns-polyamine derivatives of red blood cell extract utilizing an automated polyamine analyser. Journal of Chromatography 295, 101-108.

Chauveau, J., Clement, G., Clement-Champougny, F. \& Le Breton, E. (1951). Non-equilibrium between the lipid constituents of cellular structures in the course of initiation of experimental hepatoma in the rat cell. The lipids of rat liver fractions. Archives des Sciences Physiologiques 5, 305-322.

Dahlqvist, A. (1968). Assay of intestinal disaccharidases. Analytical Biochemistry 22, 99-107.

Diamond, J. M. (1986). Hard-wired local triggering of intestinal enzyme expression. Nature 324, 408.

Dufour, C., Dandrifosse, G., Forget, P., Vermesse, F., Romain, N. \& Lepoint, A. (1988). Spermine and spermidine induce intestinal maturation in the rat. Gastroenterology 95, 112-116.

Forget, P., Lombet, J., Grandfils, C., Dandrifosse, G. \& Geubelle, F. (1985). Lactase insufficiency revisited Joumal of Pediatric Gastroenterology and Nutrition 4, 868-872.

Georges, P., Dandrifosse, G., Vermesse, F., Forget, P., Deloyer, P. \& Romain, N. (1990). Reversibility of spermine-induced intestinal maturation in the rat. Digestive Diseases and Sciences 35, 1528-1535.

Gordon, J. I. \& Hermiston, M. L. (1994). Differentiation and self-renewal in the mouse gastrointestinal epithelium. Current Opinion in Cell Biology 6, 795-803.

Hosomi, M., Stace, N., Murphy, G. M. \& Dowling, R. H. (1985). Cellular regulation of adaptive intestinal mucosa hyperplasia: effect of the polyamine synthesis blocker DFMO. Gastroenterology 88, 1715.

Ittel, T. H., Paulus, C.-P., Handt, S., Hofstädter, F. \& Sieberth, H-G. (1992). Induction of intestinal mucosal atrophy by difluoromethylornithine: a nonuremic model of enhanced aluminium absorption. Mineral and Electrolyte Metabolism 18, 15-23.

Jänne, J., Poso, H. \& Raina, A. (1978). Polyamines in rapid growth and cancer. Biochimica et Biophysica Acta 473, 241-293.

Luk, G. D. \& Baylin, S. B. (1983). Polyamines and intestinal growth-increased polyamine biosynthesis after jejunectomy. American Journal of Physiology 245, G656-G660.

Luk, G. D., Marton, L. J. \& Baylin, S. B. (1980). Ornithine decarboxylase is important in intestinal mucosal maturation and recovery from injury in rat. Science 210, 195-198.

Moulinoux, J.-P., Darcel, F., Quemener, V., Havouis, R. \& Seiler, N. (1991). Inhibition of the growth of U-251 human glioblastoma in nude mice by polyamine deprivation. Anticancer Research 11, 175-180. 
Pegg, A. F. \& McCann, P. P. (1982). Polyamine metabolism and function. American Journal of Physiology 243, C212-C221.

Pollack, P. F., Koldovky, O. \& Nishioka, K. (1992). Polyamines in human and rat milk and infant formulas. American Journal of Clinical Nutrition 56, 371-375.

Romain, N. Dandrifosse, G., Jeusette, F. \& Forget, P. (1992). Polyamine concentration in rat milk and food, human milk and infant formulae. Pediatric Research 32, 58-63.

Schneider, W. C. (1957). Determination of nucleic acids in tissues by pentose analysis. In Methods in Enzymology, vol. 3, pp. 680-684, [S. P. Colowick and N. O. Kaplan, editors]. New York: Academic Press.

Yarrington, J. T., Sprinkle, D. J., Loudy, D. E., Diekema, K. A., McCann, P. P. \& Gibson, J. P. (1983). Intestinal changes caused by DL- $\alpha$-difluoromethylornithine (DFMO), an inhibitor of ornithine decarboxylase. Experimental and Molecular Pathology 39, 300-316. 